\title{
A "RAIES" E A REVISTA AVALIAÇÃO A CONSTRUÇÃO DE UM MARCO TEÓRICO, POLÍTICO E METODOLÓGICO'1
}

\author{
José CARLos Rothen* \\ Gladys Beatriz BarReyro**
}

Recebido: jun. 2010

Aprovado: mar. 2011

* Doutor em Educação. Professor do Departamento de Educação UFSCar. Membro do Grupo de Estudos e Pesquisa em Política e História da Avaliação da Educação Superior - GEPPHAES. São Carlos, SP, Brasil. E-mail: josecarlos@rothen.pro.br

** Doutora em Educação. Professora na Universidade de São Paulo, no Programa de Pós-Graduação em Educação (FE), no Programa de Pós-Graduação em Integração da América Latina - PROLAM) e na Escola de Artes, Ciências e Humanidades -EACH. Membro do Grupo de Estudos e Pesquisa em Política e História da Avaliação da Educação Superior - GEPPHAES. Paulo, SP, Brasil. E-mail: gladysb@usp.br

Resumo: O texto estuda o "saber" produzido por um dos grupos da rede de poder que criou as políticas de avaliação da educação superior brasileira, reconstruindo o regime de verdade que regula a distribuição dos enunciados na visão emancipatória da avaliação. Ou seja, tendo como referência Foucault: o conjunto de procedimentos regulados para a produção, a repartição, a circulação e o funcionamento dos enunciados. Toma-se como fonte a produção acadêmica publicada na Revista Avaliação pelos membros da Rede de Avaliação Institucional da Educação Superior (RAIES), no período 1996-2002 que é complementada com entrevistas realizadas a membros do grupo. Concluise que a rede elaborou e instituiu um discurso sobre a existência de uma concepção de avaliação: institucional, formativa, participativa, desenvolvendo os seus fundamentos e elaborando uma teoria dessa visão da avaliação. Essa concepção foi colocada como alternativa e contraposição ao Exame Nacional de Cursos, instaurando uma dicotomia entre duas visões de avaliação: a da avaliação institucional formativa/emancipatória e a de desempenho/resultados

Palavras-chave: Avaliação da educação superior. Concepções de avaliação. Revista Avaliação. Rede de Avaliação Institucional da Educação Superior - RAIES.

\section{THE RAIES AND THE REVISTA AVALIAÇÃO: THE CONSTRUCTION OF A THEORETICAL, POLITICAL AND METHODOLOGICAL FRAMEWORK}

Abstract: The paper examines the "knowledge" produced by one of the groups of power in the network that created policies of evaluation of brazilian higher education. It studies the regime of truth that produced a discourse about the emancipatory conception of evaluation. That is, with reference to Foucault: the set of rules for regulating production, distribution, circulation and functioning of discourses. The research is based in papers published in the Revista Avaliação, by members of Network of Institutional Evaluation of Higher Education (Raies), in the period 1996-2002 and it is complemented with interviews with group members. It is concluded that the network has developed and instituted a discourse about formative evaluation as: institutional, educational and participatory. They developed their concepts and created a theory about that conception of evaluation. This concept was put forward as an alternative and opposition to National Examination of Courses establishing a dichotomy between two conceptions: formative evaluation and control evaluation.

Key words: Evaluation of higher education .Conceptions of evaluation. Revista Avaliação Network of Institutional Evaluation of Higher Education - (RAIES).

1 Parte das análises aqui presentes faz parte da comunicação intitulada "História das Concepções de Avaliação da Educação Superior: A Revista Avaliação (1996 - 2002)" apresentada no IV Congresso Brasileiro de História da Educação. 


\section{INTRODUÇÃO}

Na década de 1980, nas discussões cujo objeto era o modelo de educação superior que deviam conformar esse sistema no país, encontram-se manifestações que vinculam concepções de avaliação da educação superior, diferentes e/ou contraditórias entre si. Ideias essas que foram desenvolvidas pelo PARU (Programa de Avaliação da Reforma Universitária, 1983), pela "Comissão de Notáveis" (Comissão Nacional para a Reformulação do Ensino Superior - 1985) e pelo GERES (Grupo Executivo de Reformulação do Ensino Superior, 1986). Nesses antecedentes, a avaliação não era o foco principal, mas um elemento da política (BARREYRO; ROTHEN, 2008). Nas décadas seguintes, 1990 e 2000, a avaliação iria adquirir centralidade nas políticas de educação superior, instaurando-se ações concretas que responderam a fundamentos diferentes, apresentando concepções distintas de avaliação e de regulação. Elas são: na década de 1990, o Programa de Avaliação Institucional das Universidades Brasileiras (PAIUB, 1993) e o Exame Nacional de Cursos (ENC-"Provão", 1997) e, na década de 2000, o Sistema Nacional de Avaliação da Educação Superior (SINAES, 2004).

Este artigo é resultado da pesquisa sobre os grupos de acadêmicos que influenciaram e participaram ativamente na formulação e implantação das políticas de avaliação. Como referência teórica utiliza-se concepções de poder e de regime de verdade propostas por Foucault (1986). Resumidamente, para Foucault não existe o poder em si, mas sim o exercício do poder; ele não se estabelece de forma vertical, mas sim, em uma rede de relações. Assim, o estudo das relações de poder consiste em identificar e explicitar os "nós" da rede a partir dos quais ocorre o seu exercício. O autor, ainda, aponta que o poder não se restringe às dimensões negativas de censura e repressão; no seu aspecto positivo, ele cria um saber e um prazer. Na opção metodológica, na pesquisa estudou-se o saber produzido pelos grupos que constituem os nós da rede de poder no qual se constituíram as políticas de avaliação. No pensamento de Foucault, não se utiliza o conceito de verdade absoluta, mas sim o conceito de Regime de Verdade; ele propõe “por 'verdade', entender um conjunto de procedimentos regulados para a produção, a lei, a repartição, a circulação e o funcionamento dos enunciados" (FOUCAULT, 1986, p. 14). Ao estudar um regime de verdade busca-se identificar os procedimentos de regulação e legitimação da distribuição dos enunciados.

Aqui, são apresentadas as concepções de um dos grupos pesquisados, no caso, a Rede de Avaliação Institucional da Educação Superior (RAIES), que edita a Revista Avaliação. A RAIES surgiu a partir da experiência do Programa 
de Avaliação Institucional das Universidades Brasileiras (PAIUB), como resposta à instauração do ENC-Provão. Suas concepções permearam, em 2002, a proposta de governo da Coligação "Lula Presidente" para a educação ("Uma escola do tamanho do Brasil”), no que diz respeito à educação superior. Alguns de seus membros, durante esse governo, fizeram parte de Comissões e ocuparam cargos no Ministério da Educação que os levaram à implantação do Sistema Nacional de Educação (SINAES) (BARREYRO, 2009).

O objetivo principal é contribuir com a reconstrução do regime de verdade que regula a distribuição dos enunciados na visão emancipatória da avaliação. Como fonte, toma-se para análise, os editoriais e os artigos dos principais atores sociais vinculados à Rede, que foram publicados na Revista Avaliação, entre os anos de 1996 e 2002. Complementa-se com entrevistas realizadas a membros do grupo no marco da pesquisa: Avaliação e Regulação da educação superior: concepções e atores. ${ }^{2}$

\section{DO PAIUB À RAIES}

O Programa de Avaliação Institucional das Universidades Brasileiras foi implantado em 1993, pela Secretaria de Educação Superior do Ministério da Educação. Ele foi produto do trabalho da Comissão Nacional de Avaliação das Universidades Brasileiras que tinha sido estabelecida pelo MEC no mesmo ano. Tal Comissão estava composta por representantes de entidades da educação superior brasileiras ${ }^{3}$, o que lhe dava legitimidade, além da heterogeneidade política de seus membros; na avaliação de Dilvo Ristoff (2009) "essa combinação de forças, fez com que essa avaliação ganhasse espaço", porque "não era o governo que estava fazendo uma nova proposta de avaliação". Destaca-se que o texto base do PAIUB, foi elaborado pela Associação Nacional de Dirigentes das Instituições Federais de Ensino Superior (ANDIFES) (TRINDADE, 2009; DIAS SOBRINHO, 2009).

\footnotetext{
2 Essa pesquisa foi desenvolvida entre 2007 e 2009, com apoio da FAPESP.

3 A Comissão Nacional de Avaliação teve os seguintes membros. Representando a Secretaria de Educação Superior - SESu: Maria José Vieira Féres (Coordenadora), Eda C. B. Machado de Sousa e Paulo Roberto da Silva. Os seguintes representantes de entidades: Hélgio Henrique C. Trindade (Associação Nacional de Instituições Federais de Ensino Superior - Andifes), João Carlos Thomson (Associação Brasileira de Universidades Estaduais E Municipais - ABRUEM), Antonio Veronezi (Associação Nacional De Universidades Particulares - ANUP), Ir Norberto Francisco Rauch (Associação Brasileira de Escolas Superiores Católicas - ABESC), Maria Amélia S. Zainko (Fórum dos Pró - Reitores De Graduação), Luiz Carlos Paviu (Fórum Dos Pró-Reitores De Pesquisa E Pós-Graduação), Júlio Wiggers (Fórum dos Pró-Reitores de Extensão) e Wrana M. Panizzi (Fórum dos Pró-Reitores de Planejamento e Administração). Como membros do Comitê Assessor participaram: Dilvo I. Ristoff (UFSC), Eda C. B. Machado de Sousa (SESu/MEC), Fernando Menezes Campello de Souza (UFPe), Heloisa Helena Sant'Anna (UEL), Isaura Belloni (UnB), Jacques Velloso (UnB), Jesus Renato Galo Brunet (UFSM), José Dias Sobrinho (UNICAMP), José Vicente Tavares dos Santos (UFRGS), Lina Cardoso Nunes (UNESA), Marlene Grilo (PUCRS), Victor Meyer (UFSC)
} 
A avaliação, segundo entendida nesse Programa, tinha função de ajudar na melhoria do desempenho das instituições; sendo considerada uma ferramenta para o planejamento e a gestão das instituições, além de ser uma forma de prestar contas à sociedade. A avaliação possuía caráter voluntário, promovendo a incorporação das instituições que assim o desejassem. A participação da própria comunidade acadêmica era outra importante característica do Programa, adquirindo um caráter endógeno; ela seria complementada com avaliação externa. O PAIUB foi estruturado segundo sete princípios: 1. Globalidade. 2. Comparabilidade. 3. Respeito à identidade institucional. 4. Não punição ou premiação. 5. Adesão voluntária. 6. Legitimidade. 7. Continuidade (BRASIL, 1993).

Entendia-se que essas características fizeram do PAIUB uma avaliação formativa, pois os resultados obtidos permitiriam reverter em função da melhoria institucional. A pesar do caráter institucional dessa avaliação, o Programa propunha que essa avaliação iniciasse pelo ensino de graduação. Essa opção iria ter uma influência posterior na política de avaliação como regulação, implantada no governo Fernando Henrique Cardoso: a avaliação seria realizada no nível dos cursos de graduação e não da instituição. (BARREYRO; ROTHEN, 2008).

O PAIUB recebeu financiamento da Secretaria de Ensino Superior do MEC e foi implementado a partir de editais abertos nos anos de 1993, 1994 e 1996. Segundo Palharini (2001), 17 universidades federais aderiram e implementaram o PAIUB, com diferentes graus de aprofundamento.

\section{A REVISTA AVALIAÇÃO}

Vários dos participantes do PAIUB coincidem em afirmar que, enquanto este era desenvolvido, eles pensavam na criação de uma revista. Denise Leite (2009) afirma: "Nas reuniões do PAIUB, nós já tínhamos certeza que precisávamos fazer a revista, aquilo era uma coisa que a gente vinha acalentando".

A Revista Avaliação teve o seu primeiro número em um momento em que as políticas públicas para a educação superior brasileira assumiram, como ponto central, a vinculação entre a expansão via iniciativa privada, a avaliação e a regulação do sistema. O ícone dos novos rumos dessas políticas foi a implantação do Exame Nacional de Cursos (Provão) pelo Ministério da Educação. A nova política sobrepôs-se a toda uma prática de avaliação que estava sendo construída no âmbito do Ministério com a ativa participação das Instituições de Educação Superior, principalmente as públicas (PALHARINI, 2003). José Dias Sobrinho (2009) relata a criação da Rede e da Revista Avaliação: 
A RAIES (Rede de Avaliação Institucional da Universidade Brasileira) e a Revista Avaliação foram criadas, no dia 26 de abril de 1996, durante um seminário que estava acontecendo na Universidade Católica de Pernambuco, em Recife. Estava presente a secretária da SESu e a presidente do INEP, Maria Helena Castro. Ela expôs as novas políticas do MEC, inclusive o "Provão", e, nós já havíamos pensado em termos uma revista, um órgão de divulgação dos nossos trabalhos. Então, aquele seminário naquele momento oportunizou a criação da revista.

Dilvo Ristoff, (2009) editor adjunto da revista manifesta que, nesse encontro realizado em Recife, para os membros do PAIUB, ficou claro que o Programa estava sendo ignorado, sem isso ser dito explicitamente, mas pela enunciação de princípios opostos aos do PAIUB, em suas palavras: "[...] eu disse (O PAIUB) morreu, morreu. Enós decidimos que nós íamos fazer uma Revista para garantir um espaço de discussão e, é claro, de contestação".

A viabilização econômica da edição do primeiro número foi possível graças à cotização entre os participantes. Segundo José Dias Sobrinho (2009):

Conseguimos arrecadar algum dinheirinho de alguns dos presentes e fizemos o primeiro número, mais ou menos improvisado. Uma semana depois, eu estive com o Dilvo Ristoff, em Santa Catarina, e discutimos o formato, os textos, a parte mais prática, operacional da revista, que já começou a circular em julho de 1996.

A Revista teria dupla função: de constituir o campo teórico da avaliação da educação superior, bem como, de ser um instrumento de resistência e de defesa do PAIUB. Foi montada uma comissão com membros do Comitê Assessor do PAIUB para levar o projeto à frente.

Os artigos do primeiro número foram os textos publicados no ano anterior na Revista Educación Superior y Sociedad, editada pela antiga CRESALC, atual IESALC, da UNESCO (PALHARINI, 2003, p. 44). Apesar de não haver relato, é possível inferir que a opção de republicar os artigos reside na ideia de viabilizar a publicação de um primeiro, número, rapidamente, no sentido político de marcar posição.

O conceito de Rede permite explicar o processo de criação da Revista. Segundo Denise Leite (2009):

[...] os primeiros números eram feitos em Campinas, o José Dias tinha conseguido lá algum apoio estratégico na Universidade de Campinas. A impressão era em Porto Alegre, e as diagramações eram feitas em Santa Catarina, quer dizer isso aí em termos de parcerias é uma coisa que não 
existe, né?![...]. Então, qualquer dúvida um telefonava, ou mandava o artigo e nós pensávamos juntos, é uma coisa muito interessante, a gente pensa que tudo funcionava como hoje e não era assim [...] nós não tínhamos as facilidades de comunicação que hoje a gente desfruta. Na época a gente não desfrutava das possibilidades atuais, a comunicação era o telefone, fax. A internet ainda não era essa facilidade”.

Dias Sobrinho (2009) completa o relato: "No primeiro ano houve duas edições, depois, nos anos seguintes, 4 edições. Pontualmente, saiam, em março, junho, setembro e dezembro, nunca atrasamos um número. Sempre com apoio apenas dos assinantes, e de algumas poucas universidades".

Baseada na visão de que a Revista não pertenceria a nenhuma instituição específica, mas a todos os que comungassem com os princípios básicos do PAIUB, foi criada a Rede de Avaliação Institucional da Educação Superior (RAIES), entidade jurídica sem fins lucrativos:

Do ponto de vista formal, legal, ela é uma associação civil sem fins lucrativos, por isso ela é registrada em cartório, tem CNPJ, enfim, ela é uma associação que tem de prestar contas anualmente de suas atividades, de seus financiamentos, e assim por diante, com reuniões formais de sua diretoria. Agora, do ponto de vista acadêmico, é uma rede um pouco fluida, que reúne pesquisadores da área de avaliação e da área de educação superior. (DIAS SOBRINHO, 2009)

No seu início, os editores da Revista estavam distribuídos por várias regiões do Brasil, por exemplo: no sul encontrava-se a professora Denise Leite, no Rio de Janeiro estava o professor Carlos Eduardo Bielschowsky, no Recife estava o professor Fernando Campello, entre outros (PALHARINI, 2003). Denise Leite (2009) afirma

Cada um estava numa ponta do Brasil [...] a Maria Amélia [Sabbag Zainko] [em Curitiba] eu [em Porto Alegre], a Isaura [Belloni] em Brasília, a Isaura era uma figura sempre presente. Ela estava presente na nossa memória em termos de conhecimento em avaliação, nem sempre presente fisicamente. Mas, ela era sempre uma referência que estava junto. E o Dilvo [Ristoff] foi uma das pessoas que cuidou de toda a parte lingüistica, revisão, ele era daqueles que escrevia bem, o José Dias [Sobrinho], também, escrevia bem; eu era metida em escrever, então éramos os 3'Ds que assim chamavam o pessoal.

Quanto às atividades da RAIES, Maria Amélia Sabbag Zaínko (2009), membro do Conselho Editorial da Revista esclarece que são 
[...] a promoção de seminários que trabalham com essa questão de criar compromisso, da publicação e da circulação das ideias e alguns livros, enfim, a promoção, a participação internacional em alguns eventos, ela é uma rede que acaba sustentando a publicação da revista.

Pergunta-se: o que é a Rede? Seria apenas um arranjo jurídico para um grupo editar a revista sem precisar vinculá-la a uma Universidade específica? Interpreta-se aqui, que intencionalmente deixa-se hermética a constituição exata da Rede. Em dissertação de mestrado orientada por José Dias Sobrinho, editor da Revista, Francisco Gonçalves Filho (2003, p. 45) aponta para uma indefinição do que consistiria a RAIES. Em suas palavras:

Ao ler a capa e a contracapa da revista Avaliação do período investigado, o leitor verá que a revista é de responsabilidade de uma associação civil sem fins lucrativos, denominada Rede de Avaliação Institucional da Educação Superior - RAIES. Na revista não encontramos nenhum detalhamento sobre a constituição da rede, mas algumas pistas de suas intenções e propostas.

Essa indefinição permitiu que a RAIES e a Revista se confundam, isto é, exatamente na Revista que se dá a constituição da Rede, onde os autores comprometidos com os princípios do PAIUB expressaram as suas experiências, por um lado, o espaço no qual foram elaboradas as referências teóricas sobre a avaliação e, por outro, a arma de resistência à política de avaliação governamental.

Alguns indícios que solidificam essa hipótese

a) Em sua totalidade, excluindo um, os membros brasileiros do conselho editorial da Revista e os seus editores participaram do Conselho Assessor do PAIUB ${ }^{4}$.

b) O editorial do primeiro número vincula a Revista ao PAIUB. Nos termos do editorial:

Esta revista é mais uma iniciativa para consolidar e enriquecer esse programa nacional, que hoje já se apresenta como uma das mais férteis e promissoras iniciativas articuladas entre o MEC e as ins-

4 No site http://www.mtm.ufsc.br/ raies/ no qual são apresentados os sumários até o exemplar relativo ao Ano 7 - número 1 (23) - março de 2002 tem-se a seguinte ficha técnica. Editor: José Dias Sobrinho Unicamp/PUC-PR Editor Adjunto: Dilvo I. Ristoff - UFSC o Conselho Editorial anunciado é composto por Almerindo Janela Afonso - Univ. do Minho, Portugal; Axel Didriksson Takayanagui - UNAM e UAEM; Carlos Pedro Krotsch - U. Buenos Aires, Argentina; Carlos Eduardo Bielschowsky - UFRJ; Carmen GarcíaGuadilla - Universidade Central e CENDES, Venezuela; Denise Balarine Cavalheiro Leite - UFRGS; Fernando Menezes Campello de Souza - UFPE; Heloísa Helena Nunes Sant'Ana - UEL; Isaura Belloni UnB; Jean-Claude Régnier - Universidade de Lyon II, França; José Félix Angulo - U. Cadiz, Espanha; Maria Amélia Sabbag Zainko - PUCPR; Newton César Balzan - Unicamp e PUCC; Pedro Goergen - Unicamp; Rafael Guarga - U. de la República. 
tituições que reúnem a comunidade científica e acadêmica do país. (DIAS SOBRINHO, 1996a, p. 6).

c) Ainda no editorial, ao definir o termo avaliação institucional, se afirma que essa não se confunde com exames nacionais, como os vestibulares e o Provão.

d) A não vinculação da Revista a uma instituição, mas sim a uma Rede de investigadores;

e) E finalmente o objetivo expresso da Revista é o de

organizar uma rede, que estamos chamando de Rede de Avaliação Institucional da Educação Superior, cujo objetivo é contribuir para o desenvolvimento de políticas e instrumentos de solidariedade, de intercâmbios, e de cooperação entre instituições" (DIAS SOBRINHO, 1996a, p. 7).

Na ementa da publicação divulgada no site da Revista é evidenciada a sua missão política

A revista AVALIAÇÃO é um instrumento de organização, articulação e comunicação da Rede de Avaliação Institucional da Educação Superior, cujo objetivo é contribuir para o desenvolvimento de políticas e instrumentos de solidariedade, de intercâmbios e de cooperação entre instituições. Ela é propriedade e responsabilidade de todos os que, nas diversas instituições superiores, universidades ou não, federais, confessionais, particulares, estaduais ou municipais, estão envolvidos com os processos de avaliação, com a firme convicção de que esta responde efetivamente a um imperativo ético de transparência pública e constitui-se um instrumento valioso para a melhoria das instituições e fortalecimento dos sistemas. AVALIAÇÃO quer provocar e catalisar esses esforços, não só registrá-los e divulgá-los.

Na primeira parte da ementa tem-se a aspiração política com a publicação da revista, isto é, ela é apresentada como "um instrumento de organização, articulação e Comunicação da Rede de Avaliação Institucional da Educação Superior". A sua ação teria dupla direção, em sentido mais amplo, as políticas e, em sentido mais restrito, a cooperação entre as instituições.

Os autores da ementa, ao apresentarem a Revista como pertencente e de responsabilidade de um grupo maior que os seus editores, explicitam que a revista será alinhada com uma concepção específica das funções da avaliação, a de que ela "responde efetivamente a um imperativo ético de transparência 
pública e constitui-se em um instrumento valioso para a melhoria das instituições e fortalecimento dos sistemas". Segundo Dias Sobrinho (2009), sempre houve a intenção de "[...] mantermos uma linha editorial que defendesse a avaliação qualitativa, participativa, democrática, não punitiva, que consolidasse o campo da avaliação. Eu diria que até hoje temos essa preocupação, sempre vamos fazer isso porque a construção desse campo continua".

\section{CARACTERÍSTICAS DA REVISTA}

Durante os primeiros 6 anos a revista teve formato parecido com as revistas vendidas em banca de jornal. A capa dos números 1 a 9 possuía um desenho de um tiro ao alvo com uma flecha no centro. Ao redor são mencionados os princípios do PAIUB. No número 1, aparece o nome AVALIAÇÃO (destacado em tamanho grande) e o subtítulo "Revista da Rede de Avaliação Institucional da Educação Superior" e nos números seguintes: 2 a 10 só aparece o nome AVALIAÇÃO na capa, sem menção à Rede. Desde o número 11 até o número 22 (1999-2001), muda a tipografia do nome AVALIAÇÃO e volta a aparecer o subtítulo "Revista da Rede de Avaliação Institucional da Educação Superior"; ao mesmo tempo em que o desenho muda para uma grande lâmpada que tem o contorno de uma cabeça humana de perfil. Ao redor, novamente, aparecem os princípios do PAIUB. A partir do número 23 (2002) a revista adquire formato de livro, de cor azul durante esse ano, com o nome AVALIAÇÃO (destacado pelo tamanho da fonte) "Revista da Rede de Avaliação Institucional da Educação Superior" sem desenho gráfico, mas com o nome dos autores dos artigos consignados na capa de cada número. Esse continua sendo o formato atual da revista (2010) mudando de cor a cada ano.

Até o último número de 2006 (42), a revista era distribuída pela Universidade Estadual de Campinas, sendo que a partir de 2007 passou a sê-lo pela Universidade de Sorocaba. Foi de frequência trimestral, assiduidade destacada pelo Editor para favorecer o intercâmbio e resultados das experiências do PAIUB, em andamento no surgimento da revista. A partir de 2008 torna-se quadrimestral. Nas palavras de José Dias Sobrinho (2009) a explicação da mudança:

Por que a UNISO? Por uma necessidade mesmo. [...] Eu acho que foi uma solução muito boa para os dois lados, tanto para a RAIES, como para a UNISO, porque a UNISO ganhou uma revista já consolidada, já com nome e conseguiu melhorar essa revista do ponto de vista da apresentação, da divulgação e da normalização. Agora a revista está no SciELO... Que é uma grande coisa. 
Em dezembro de 1997, foi lançado o caderno CIPEDES, como uma separata da Revista Avaliação. Em uma notícia, escrita por Dias Sobrinho e Ristoff, é informada a criação do Centro Interdisciplinar de Pesquisas da Educação Superior (CIPEDES) coordenado por Hélgio Trindade. O objetivo do CIPEDES foi o de difundir e debater a literatura mais ampla sobre educação superior. Hélgio Trindade (2009) relembra:

Nesse momento eu e o Dilvo discutimos o seguinte: "Olha a avaliação é ótima, mas além da avaliação tem o problema da educação superior, que é um problema muito mais geral, nós não podemos passar o tempo todo só falando nisso". Então, foi proposta a ideia de nós criarmos o encarte na Revista Avaliação para tratar desses assuntos ligados à educação superior. E eu fiquei como responsável por isso. Essas separatas foram muito bem, eu tinha que fazer em casa. Então, eu preparava, conseguia os artigos e mandava para Santa Catarina, onde era impresso numa editora. O CIPEDES também foi responsável pelo livro: "Universidade em Ruínas".

Nesse período 1996-2002, houve a publicação de 8 boletins do CIPEDES, (nos números 8, 10, 13, 14, 15, 17 e 19) ${ }^{5}$.

Entre 1996 e 2002, foram publicadas 26 edições da revista que continham: editoriais, artigos, resenhas, relatórios, citações e referências bibliográficas, notícias, manifesto público, apresentação e editoriais do CIPEDES, somando 361 textos no total (308) dos quais são artigos acadêmicos.

No levantamento realizado por Ariana S. Santana (2009) destaca-se que, no mesmo período, houve a participação de 239 autores. Entre eles, alguns que se destacam pelo maior número de textos publicados. São eles:

- José Dias Sobrinho que, como editor chefe da Revista, escreveu no total 25 dos 26 editoriais que foram publicados, além de 10 artigos, 4 citações bibliográficas, 1 resenha e 1 notícia assim intitulada, escrita com Dilvo Ristoff.

- Dilvo Ristoff, editor adjunto da Revista, escreveu 9 artigos, 2 editoriais do caderno CIPEDES, 1 notícia escrita com o editor da Revista e 1 relatório.

- Hélgio Trindade redigiu a apresentação do caderno Cipedes, 3 editoriais do mesmo, e 4 artigos.

5 Houve variadas publicações em espanhol, de especialistas da América Latina (Garcia Guadilla, Roberto Rodriguez Gomes, Pablo Casanova, Pedro Krosch, Marcela Mollis ). Também publicaram vários especialistas brasileiros (Marilena Chaú, Luiz Antônio Cunha, Valdemar Sguissardi, Afrânio Mendes Catani). 
- Afrânio Mendes Catani e Renato Dagnino escreveram 5 artigos, e João Ferreira de Oliveira teve 4 artigos publicados.

- Denise Leite, como já citado, organizou uma das 26 edições da Revista no período analisado, elaborando o editorial, além de contribuir com 3 artigos.

- Valdemar Sguissardi publicou 3 artigos e 1 resenha.

- Maria Amélia Sabbag Zainko, Maria do Carmo de Lacerda Peixoto, Aluí Oliveira Barbisan, Stela Maria Meneghel, Alberto Noé, Luiz Antônio Cunha, Hernán Thomas e José Tomaz Vieira Pereira, todos publicaram 3 artigos.

- Ivo José Both publicou 2 artigos e 1 relatório.

Ainda, se tem que 28 autores publicaram dois textos cada um e, a maior parte dos autores (196) publicou apenas 1 texto.

Entre esses nomes, vemos que muitos dos autores que mais publicaram na Revista são ou editores, como José Dias Sobrinho e Dilvo Ilvo Ristoff, ou fizeram parte do conselho editorial, como Maria Amélia Sabbag Zainko, Denise Leite e, como observado, continuaram fazendo parte da Revista com suas contribuições (SANTANA, 2009, p. 15).

\section{O REGIME DE VERDADE DA REVISTA}

A argumentação dos editoriais ${ }^{6}$ e de boa parte dos artigos foi construída tendo como estrutura básica a afirmação de sua postura e a contraposição às posições vinculadas aos defensores do modelo de avaliação adotado a partir do Exame Nacional de Cursos. Na reconstrução dos princípios que regulam a distribuição dos enunciados na Revista far-se-á inicialmente a exposição da "afirmação" e na sequência a reconstrução da "contraposição"

6 É importante ressalvar que os editoriais foram assinados pelo seu editor, José Dias Sobrinho, com exceção do número 8 (v.3, n.2, jun. 1998) que foi realizado por Denise Leite, membro da Rede e quem também organizou esse número em que, coincidentemente começou a publicação da separata do CIPEDES. Além do mais, o seu editor, junto com Dilvo Ristoff foram os autores que mais artigos publicaram na Revista. O leitor deste artigo pode perguntar-se, então trata-se das posições de um autor específico ou de um grupo? Com certeza, as ideias expressas no editorial e nos artigos analisados representam o pensamento do seu autor, mas por estarem inseridos em uma Revista que, efetivamente articula um grande número de autores, assume-se aqui a hipótese de que as posições defendidas representam em linhas gerais as ideias dos defensores do PAIUB. 


\subsection{A afirmação}

Diversas vezes, nos editoriais da Revista, retoma-se o propósito de construirse uma área de estudos: a avaliação institucional da educação superior. No primeiro editorial, ao delimitar essa nova área de estudo, são utilizados três termos: a) avaliação; b) institucional; c) educação superior. A estes se soma o termo PAIUB, o qual é apresentado como modelo de referência. Estes quatro termos serão utilizados como fio condutor da reconstrução dos fundamentos dessa nova área.

\subsubsection{Educação superior}

Comecemos pelo terceiro termo. Na proposta dos editoriais, o novo campo não se refere à avaliação da educação como um todo, mas sim se delimita a educação superior. Com essa delimitação não se pretendeu negar que ocorra a avaliação de instituições escolares em outros níveis da educação, mas sim quer se afirmar que há uma especificidade nesse tipo de avaliação que apenas surgiu e somente tem sentido nas Instituições de Educação Superior. Assim, no decorrer dos editoriais, fica claro que essa especificidade estaria intimamente relacionada com a autonomia universitária, isto é, que a avaliação institucional exigiria uma autonomia que só é possível na educação superior.

Apesar de ser um pressuposto importante, o conceito de autonomia é pouco discutido no material analisado. Quando a discussão aparece, ela está inserida na tradicional tensão na relação entre o Estado e a Universidade. A autonomia é apresentada como um processo de desregulação e descentralização, o qual seria oposto à normatização (regulação e centralização). (DIAS SOBRINHO, 1998). Normalmente, o discurso da autonomia está implícito nas críticas que são feitas à influência dos órgãos multinacionais (por ex. o Banco Mundial) e das políticas educacionais visando atender as demandas do "mercado".

Repetidas vezes, nos editoriais, está presente a ideia do "caráter público do ensino, do saber, da pesquisa e da formação" (DIAS SOBRINHO, 1996a, p. 5-6). Na visão da Revista o "público" não coincide com o estatal, e nem com o privado, mas sim com a construção coletiva da sociedade. (DIAS SOBRINHO, 1999a). O caráter público é um dos imperativos que justificaria a necessidade da avaliação institucional, pois pelo fato de as instituições terem esse caráter, é premente o compromisso ético da visibilidade institucional. A partir dessa ideia, defende-se que a obrigação da universidade ser sensível às demandas sociais não significaria que ela deve se sujeitar às regras do mercado (DIAS 
SOBRINHO, 2000). Assim, o processo de avaliação não poderia ser algo que seja restringido a algumas pessoas ou até à própria instituição; todo o processo como os seus resultados, obrigatoriamente, teriam de ser públicos.

Diante do possível questionamento de que existem instituições públicas, confessionais e privadas, nos editoriais é presente a ideia de que o caráter público não é garantido por quem a provê, mas sim pela função social que ela cumpre. Não importaria que a instituição fosse estatal ou privada, ela teria que cumprir a sua função e, por isso mesmo, passar por processos públicos de avaliação. Nesse contexto, uma instituição não poderia esconder informações por motivos mercadológicos. Aqui, não se defende a privatização da educação, ao contrário ela é criticada por contrariar o caráter público ao estar dirigida ao cliente ao invés de à formação dos estudantes (DIAS SOBRINHO, 1999a).

O que é a educação superior? Qual modelo ideal de instituição? Nos textos selecionados, essa questão é discutida principalmente por Ristoff e Dias Sobrinho. Os dois autores afastam-se da ideia de que exista um modelo único a ser seguido. Nitidamente, não aceitam a ideia de que a educação superior deva se restringir à universidade de pesquisa ou, no seu oposto, à instituição exclusivamente destinada à formação profissional.

Segundo Ristoff(1999), a universidade brasileira estaria passando uma tripla crise: a financeira, a do modelo de universidade e a do elitismo. A crise financeira relacionada principalmente com os cortes do financiamento da educação no governo Fernando Henrique Cardoso.

A crise do modelo de universidade se daria pelo fato de que ela não estaria atendendo às seguintes demandas: o avanço do conhecimento desatrelado das necessidades imediatas, as exigências do Estado, vinculadas aos projetos de desenvolvimento e à necessidade social de mão de obra qualificada, e por último, o interesse dos indivíduos em investir na própria formação. Essas demandas só seriam atendidas pela adoção de diversos modelos de instituição. Nesta visão se aceita a ideia da criação de instituições destinadas prioritariamente ao ensino. O que não significa dizer que ela deva dedicar-se exclusivamente à formação profissional, a atender simplesmente as exigências do mercado; nesse sentido, Ristoff (2001) opõe a universidade de verdade à operacional, afirmando que ela deveria formar o cidadão altamente qualificado ao invés de formar o bárbaro altamente qualificado. No mesmo sentido, Dias Sobrinho (1998a), ao analisar o tipo de pesquisa realizada na universidade, aponta que são necessárias instituições que realizem pesquisa de ponta, mas ao mesmo tempo, é necessário que seja valorizada a pesquisa ligada à realidade local, que tenha função pedagógica e pertinente ao meio em que está inserida. 
A democratização do acesso à educação superior, segundo Ristoff (2001), estaria ocorrendo de forma perversa e elitista, pois a expansão da educação superior via iniciativa privada permitiria ter acesso ao nível superior apenas àqueles que podem pagar. Independentemente do modelo da universidade adotado, teria que ocorrer a expansão, com qualidade, da universidade pública e gratuita.

Ao definir-se o novo campo do conhecimento - a avaliação institucional não se utiliza o termo universidade, mas sim educação superior. Esta opção não é acidental, pois se defende a ideia de que a diversidade institucional é que atenderia à sociedade. Assim, na avaliação da educação superior, seria fundamental o respeito à identidade institucional, de compreendê-la inserida "no contexto das inúmeras diferenças existentes no país" (RISTOFF, 1996, p. 49).

\subsubsection{Institucional}

O termo institucional também é fundante dessa nova área. Ele determina tanto o objeto da avaliação, que é a instituição no seu todo, como o sujeito, o avaliador, que é ela própria. No sentido de explicitar o princípio presente no conceito, façamos, aqui, uma comparação com a medicina. Aparentemente nessa área de estudo o sujeito e o objeto de estudo são os mesmos, o ser humano. Dizemos aparentemente, pois o cientista das investigações médicas não se vê como o seu objeto de estudo; o corpo vivo, ou não, estudado não é ele próprio, mesmo se ele utilizar o seu corpo como cobaia. O termo institucional aqui indica que aquele que investiga a si próprio se vê como investigado, isto é, como sujeito/objeto envolvido no processo. O envolvimento fundamenta-se na decisão política/ética de se avaliar. Nas palavras do editorial

Institucional se refere, ao sujeito, ao objeto e à relação entre um e outro, ou seja, ao modo como o processo se realiza. Dizemos que o sujeito é institucional no sentido de que são os agentes da própria instituição e da comunidade cientifica, social e institucionalmente constituídos e, então, legitimados, que realizam o processo. Os sujeitos de avaliação é a instituição, a plenitude de suas estruturas e relações internas e externas. Os sujeitos da avaliação constroem um projeto ou desenho e produzem praticamente um processo segundo os critérios, objetivos e procedimentos públicos da comunidade, isto é, à maneira institucional e com os dispositivos da instituição (DIAS SOBRINHO. 1996a, p. 5). 
O termo titularidade é intimamente vinculado ao institucional. Em diversos momentos frisa-se a ideia de que a avaliação tem a instituição como titular. Rejeita-se a ideia de que os titulares dessa avaliação possam ser exógenos, isto é, nem a Sociedade, nem o Estado, nem alguma outra agência são titulares dessa avaliação. A sensibilidade às demandas sociais, o diálogo com o Estado e a possibilidade do uso de avaliações de agências externas não transferem essa titularidade.

A avaliação institucional seria a ação de autoconhecimento de uma instituição que abriga diversos interesses e visões de educação. A diversidade interna seria decorrência da heterogeneidade de valores presentes. Assim, segundo Ristoff (1996) a avaliação teria a função de firmar valores. Dias Sobrinho (2001, p. 8) defende a ideia de "que a avaliação não é mono-referencial" e por estar "mergulhada em ambiguidades e tensões [...] ela não pode produzir certezas ou resposta finais". Nesse contexto a avaliação é uma questão ética, tanto na sua decisão de ocorrer como no tipo de resultado que se alcança. A avaliação seria atribuir valores, os seus resultados são condicionados pelos valores adotados.

A avaliação multi-referencial só seria possível se fosse superada a visão de controle. No embate democrático com respeito à diferença, a avaliação consistiria num processo de crítica no qual, com autonomia intelectual, temse o aumento da consciência dos limites e das potencialidades institucionais (DIAS SOBRINHO, 1998b; 2001). A decisão ética de promover o autoconhecimento institucional por meio da avaliação contribuiria para a emancipação da instituição.

Uma das dificuldades no uso do adjetivo institucional é a célebre questão de se saber se a avaliação deve assentar-se em valores e conhecimentos locais ou, ao contrário, em referências universais. A proposta recorrente seria de buscar a conciliação entre o universal e o local. A adoção exclusiva de valores locais levaria ao isolamento institucional e, além do mais, desconsideraria os impactos que as ações locais têm num mundo globalizado; por sua vez, a exclusiva adoção de valores universais, ao contrário, abafaria "identidades regionais e as expressões culturais de etnias e grupos humanos constituídos localmente" (DIAS SOBRINHO, 1998a, p. 28).

\subsubsection{Avaliação}

Na discussão do que é avaliação estão presentes os seguintes princípios básicos: a titularidade da instituição, a vinculação da avaliação à atribuição 
de valores e a ideia de que ela é uma ação política. A estrutura argumentativa dos textos, de forma predominante, dirige-se no sentido de superar a visão dicotômica entre emancipação/competência técnica, legitimidade política/ neutralidade e qualidade/quantidade.

É recorrente tanto a ideia de que a avaliação comporta aspectos técnicos para a sua realização, como a crítica à visão de que estes deveriam ser predominantes. Nesse sentido, Dias Sobrinho (1996) aponta que a avaliação "quase" tem um caráter científico e técnico, mas é efetivamente uma ação política, isto é, os dados objetivos seriam fundamentais como subsídio à avaliação, mas não seriam a avaliação. A necessária credibilidade técnica dos instrumentos não seria suficiente para legitimar a avaliação, o que efetivamente a legitimaria seriam os significados dados pela comunidade institucional. Segundo Dias Sobrinho, os processos de avaliação

deverão desenvolver-se segundo uma racionalidade técnica, que assegure informações objetivas e críveis, mas também é imprescindível que cumpra com os requisitos da eqüidade, tais como a ausência de coerção, a construção de garantias de respeito aos sentidos produzidos socialmente, a liberdade de expressão, a participação e sobretudo colabore para a justiça social e não para a desigualdade e a exclusão (DIAS SOBRINHO, 2001, p. 8).

A credibilidade técnica e a objetividade não implicariam, nessa visão, em uma avaliação neutra, pois a sua realização teria como objetivo produzir efeitos determinados por valores preconcebidos. O que se desejaria seria uma avaliação imparcial ao invés de neutra, ausente de valores. Afirma-se assim a temporalidade da avaliação, ela seria situada em "contextos humanos cheios de representações e valores e se destina a cumprir interesses de determinados destinatários" (DIAS SOBRINHO, 2001. p. 14).

A superação da oposição qualidade/quantidade se dá na crítica à ideia de que os aspectos quantitativos da avaliação seriam suficientes. Na Revista, predomina a ideia de que a simples expressão da quantidade não é a expressão da qualidade. Esse reducionismo é criticado principalmente porque a avaliação seria um "instrumento poderoso de qualificação dos processos educativos e das relações escola-sociedade" (SORDI, 1998, p. 53).

A avaliação, na visão da Revista, seria um processo político de atribuição de valores; para tanto faria uso da objetividade técnica e de dados quantitativos. Essa postura leva a um outro conceito: a avaliação é um instrumento de emancipação das instituições. Emancipação é um conceito chave: a avaliação 
permitiria "elevar a consciência dos problemas, potenciar os sentidos dos fenômenos e projetar novas possibilidades de construção. Contribua para a emancipação, portanto" (DIAS SOBRINHO, 2001, p. 11).

No editorial do número de março de 2001, afirma-se que a avaliação institucional não seria simplesmente um balanço do que foi realizado nem apenas dos resultados alcançados, mas a busca da compreensão das causas, baseada num processo de interrelações, de comunicação democrática, numa instituição plural. $\mathrm{O}$ aspecto democrático da avaliação permitiria que os participantes do processo fizessem efetivo uso dos resultados obtidos.

Além de constituir-sem uma área de conhecimento, a avaliação institucional da educação superior seria uma "prática arraigada permanentemente nas instituições educativas" (DIAS SOBRINHO,1996a, p. 5). A ênfase de que a avaliação é uma prática é derivada do conceito de titularidade, pois a construção dos modelos de avaliação se daria nos embates internos das instituições, a constituição teórica dessa nova área seria dos agentes envolvidos na prática da avaliação e não uma construção teórica externa ao meio no qual ela ocorre.

Finalmente, o processo emancipatório da avaliação teria como objetivo, nas palavras de Belloni (1996, p. 8), "o autoconhecimento e a tomada de decisão com a finalidade de aperfeiçoar seu funcionamento e seus resultados", o que segundo Trindade (1996 p. 12) significaria "o aperfeiçoamento da qualidade acadêmica; a melhoria da gestão universitária e a prestação de contas à sociedade".

\subsubsection{PAIUB}

A referência principal das proposições apresentadas na Revista, pelo menos no período estudado, é o Programa de Avaliação Institucional das Universidades Brasileiras (PAIUB). Em vários momentos o PAIUB é apresentado como um programa que valorizava e respeitava a decisão institucional de promover a autoavaliação.

Ao analisar a implantação do PAIUB, Denise Leite (1997) apresenta a ideia de que a relação da Universidade com o Estado, em muitos momentos, seria de submissão e, em outros, reativa às normativas provenientes do Estado. No caso do PAIUB, ela afirma que a universidade teria antecipado e levado a cabo, no Ministério, uma avaliação marcada pela negociação do formato a ser adotado. Ela ressalva que, apesar da antecipação pela comunidade acadêmica, o PAIUB não seria hegemônico pois, na época, havia pelo menos mais cinco outras pro- 
postas no Ministério. Desta constatação, infere-se, aqui, que a construção de um modelo de avaliação que tem como fundamento a autonomia acadêmica implicaria no embate com outras propostas.

Representativo do poder emblemático e agregado do PAIUB é o fato, como assinalado, que, na capa dos primeiros números da Revista, são apresentados graficamente os princípios fundamentais do PAIUB, que constituem os fundamentos da nova área, são eles: globalidade, comparabilidade, legitimidade, identidade, continuidade, adesão voluntária, não punição e nem premiação. Esses princípios da avaliação estão vinculados com dois conceitos basilares da concepção de universidade adotada: a educação como bem público e a autonomia universitária

\subsection{A contraposição}

Na Revista, a delimitação da área da avaliação institucional também ocorre a partir da crítica ao modelo concorrente ao PAIUB, ou seja, ao Exame Nacional de Cursos (Provão). Parte relevante dos editoriais e dos artigos caracteriza a visão contrária com o objetivo de opor-se a ela. Ressalta-se que apesar da crítica ao Provão ser recorrente e tornar-se o ícone de oposição, a condenação é para toda a política para a educação superior, implantada no governo Fernando Henrique Cardoso e, dentro dela, a crítica dirige-se ao papel que a avaliação cumpre no novo desenho de Estado implantado.

A oposição básica da caracterização consiste em definir a função primordial da avaliação. Na visão do PAIUB, adotada pela Revista, a avaliação seria um ato de emancipação das instituições, enquanto que na outra postura teria a função de controle externo da universidade. Os agentes do controle externo seriam o Estado e o "mercado".

Segundo os editoriais, concomitante à diminuição de "investimentos do Estado em políticas sociais, notadamente na educação" (DIAS SOBRINHO, 1996a, p. 6) a avaliação tomou corpo. Nesse contexto, o Estado deixaria de ser Provedor e passaria a ser Avaliador, sendo a avaliação compreendida como forma de controle e de contraponto da autonomia universitária (DIAS SOBRINHO, 2001b). Os critérios acadêmicos seriam deixados de lado e o que passaria a contar seriam os relativos ao aumento da produtividade acadêmica, seguindo a lógica do "mercado". (DIAS SOBRINHO, 1998b).

Em relação à educação superior, o "mercado" assumiria dupla função: a primeira, de apresentar as demandas às quais a universidade deveria atender; 
a segunda, em apresentar o modelo a ser seguido: a competição entre as instituições ao invés da solidariedade, bem como, a busca de padrões de qualidade definidos externamente. (DIAS SOBRINHO, 1999b). Nos termos dos editoriais, tem-se a seguinte crítica a essa visão:

A universidade deve ser sensível às demandas sociais. Entretanto, isso não deve significar adesão à marketização da educação baseada na crença de que as novas metáforas do mercado produzirão uma qualidade maior do ensino, da pesquisa e da extensão. (DIAS SOBRINHO, 2000).

Muitas das críticas da Revista dirigem-se às políticas orientadas por propostas do Banco Mundial, o qual compreenderia que a avaliação seria um instrumento derivado do pacto estabelecido entre a universidade e o mercado (DIAS SOBRINHO, 1996b). A avaliação condicionada pelo mercado levaria à definição de padrões internacionais e nacionais que, por sua característica produziriam "esquemas intelectivos" que "sejam operacionalmente simples" (DIAS SOBRINHO, 1997). Dessa forma, a avaliação promovida pelo Estado Avaliador não conseguiria captar o que é essencial, ou seja, não toca nos aspectos mais complexos dessa instituição que, por natureza seria plural.

Essa crítica à simplificação poderia ser rebatida pelo fato de que com ela seria possível a comparação entre as Instituições de diversos países. Porém, a crítica da Revista não é à ideia de comparação, tanto que essa é um dos princípios do PAIUB. O que os editoriais criticam é que a comparação seria no sentido da competição. Está implícito, na visão da Revista, que se o objetivo da comparação for a solidariedade, não é necessário simplificar artificialmente o que é complexo.

O Estado Avaliador, ao enfatizar o controle mediante o uso de mecanismos simplificados, segundo os editoriais, também dá uma objetividade aos indicadores de qualidade que eles não têm (DIAS SOBRINHO, 1997). Em relação a essa pretensa objetividade, encontra-se na Revista a ideia de que a universidade é uma comunidade de comunicação e a sua avaliação não pode ser diferente, sendo ela um "movimento intersubjetivo" (DIAS SOBRINHO, 1996a).

Segundo Belloni (1996), a simplificação dos resultados da avaliação além de serem frágeis serviria apenas para a elaboração de "rankings" e a padronização de uma política elitista. Ela aponta não haver fatos empíricos que confirmem a afirmativa neoliberal de que a elaboração de rankings levaria a um aumento da qualidade da educação. Nessa linha de raciocínio, Ristoff (1997) diz que os rankings divulgados pela imprensa seriam recebidos pela sociedade como 
um fato científico e esta passaria a pautar o seu comportamento em uma falsa imagem das instituições criada pela avaliação simplificadora.

Em diversos momentos, a Revista se coloca como objetivo o de contribuir para a consolidação de uma cultura de avaliação. Os editoriais, além de estarem reiterando o princípio de continuidade proposto no PAIUB, também parecem querer afastar a censura de que os críticos do Estado Avaliador não desejariam avaliar. Entende que a cultura de avaliação defendida não é a do conhecimento da realidade institucional mediante o uso de alguns indicadores com abrangência nacional, mas sim a instalação de um processo contínuo de reflexão sistemática e radical (DIAS SOBRINHO, 1996a).

Diante da questão de ser possível ou não a articulação da avaliação com enfoque coercitivo, controlador e indutora da competição, com a visão emancipatória, Dias Sobrinho (2001) aponta ser complicada, pois os valores ligados à competitividade acabam sobrepondo-se aos valores institucionais.

Finalmente, tem-se que o Exame Nacional de Cursos (o Provão), como o ícone da política governamental, foi duramente criticado nos editoriais da Revista em dois sentidos: o primeiro, indicando a limitação de pretender-se avaliar as Instituições por via de um instrumento simplificador da realidade institucional (DIAS SOBRINHO, 1996a), o segundo, ao tornar-se centro das práticas de avaliação governamental houve uma "desvalorização oficial do PAIUB” (DIAS SOBRINHO, 1998, p. 7).

\section{CONSIDERAÇÕES FINAIS}

A RAIES constituiu-se ao redor da Revista Avaliação, na qual o objetivo foi além de publicar artigos relacionados com a avaliação da educação superior. Um dos seus objetivos principais foi criar um espaço formado por uma rede de intelectuais que defendiam a concepção emancipatória da avaliação. No período estudado, a RAIES pautou a linha editorial da Revista como instrumento para a constituição e divulgação de um regime de verdade sobre a questão da avaliação da educação superior.

No âmbito da definição das políticas de avaliação, a RAIES, distanciando-se de uma visão panfletária, criou e divulgou um discurso sobre a existência de uma concepção de avaliação institucional, formativa, derivada dos princípios do PAIUB e desenvolveu seus fundamentos. Ou seja, formulou teoria dessa visão da avaliação. Essa concepção foi colocada como alternativa e contraposição ao "Provão", instaurando uma dicotomia entre duas visões de avaliação da educação superior: a da avaliação institucional formativa/emancipatória e 
a de desempenho/resultados. Assim a RAIES, por meio da Revista, cumpriu o relevante papel de contraposição a um outro discurso, hegemônico, o da privatização e do fomento à criação de instituições de educação superior privadas, introduzindo um resgate da função pública da educação e um esforço de argumentação nesse sentido. Pois para a RAIES, as Instituições de Educação Superior cumprem uma função pública e, portanto, devem se avaliar. Mas, a RAIES, na Revista não considera que elas, apesar de exercerem uma atividade que é pública - a educação -, atuam como instituições com interesses mercantis e têm como um dos seus objetivos primordiais "dar rentabilidade aos seus acionistas". Apesar do regime de verdade que regula a distribuição dos enunciados da Revista, não inclui a regulação nem a sua vinculação com a avaliação, provavelmente por estar ainda muito atrelada à visão do PAIUB, em que a participação era voluntária e sem conseqüências regulatórias.

O regime de verdade construído pela RAIES, na Revista Avaliação tornouse referência para a proposta do Sistema Nacional de Avaliação da Educação Superior (SINAES), elaborada pela Comissão Especial de Avaliação, instituída no início do governo Lula, em 2003 e parcialmente incorporadas na lei 10891/04 do SINAES: avaliação institucional (com auto-avaliação). Porém, no meio do processo de implantação do SINAES, novos resultados simplificados (índices) e novos rankings foram implantados, em 2008, numa tentativa de retorno das concepções de avaliação de resultados. Assim, a sobrevivência da avaliação institucional formativa, nas políticas de avaliação da educação superior, ainda é uma questão em disputa.

\section{REFERÊNCIAS}

BARREYRO, Gladys Beatriz. Todos ganham? Os participantes na elaboração das políticas para a educação superior no primeiro governo Lula. Ciência em movimento, Porto Alegre, v. 11, n. 22, p. 85-95, 2009.

BARREYRO, Gladys Beatriz; ROTHEN, José Carlos. "SINAES" contraditórios: considerações sobre a elaboração e implantação do Sistema Nacional de Avaliação da Educação Superior. Educação \& Sociedade, Campinas, v. 27, n. 96, p. 955-977, especial, 2006

BARREYRO, Gladys Beatriz; ROTHEN, José Carlos. Para uma história da educação superior brasileira: análise dos documentos do PARU, CNRES, GERES e PAIUB. Avaliação, Campinas; Sorocaba, v. 13, n. 1, p. 131-152, mar. 2008. 
BELLONI, Isaura. A universidade e o compromisso da avaliação institucional na reconstrução do espaço social. Avaliação, Campinas, v. 1, n. 2, p. 5-14. dez. 1996

BRASIL. Secretaria de Educação Superior - MEC. Documento Básico Avaliação da Universidade Brasileira: uma proposta nacional. Brasília, 1993 DIAS SOBRINHO, José. Avaliação institucional: marcos teóricos e políticos. Avaliação. Campinas, v. 1, n. 1, p 15-24, jul. 1996.

DIAS SOBRINHO, José. Editorial. Avaliação, Campinas, v. 1, n. 1, jul. 1996a.

DIAS SOBRINHO, José. Editorial. Avaliação, Campinas, v. 1, n. 2, dez $1996 b$.

DIAS SOBRINHO, José. Editorial. Avaliação, Campinas, v. 2, n. 2, jun 1997.

DIAS SOBRINHO, José. Editorial. Avaliação, Campinas, v. 3, n 1, mar. 1998.

DIAS SOBRINHO, José. O ensino de graduação e a pesquisa: construção e reconstrução do conhecimento e sociedade. Avaliação, Campinas, v. 3, n. 3, p. 21-30, set. 1998a.

DIAS SOBRINHO, José. Avaliação Institucional da Educação Superior. Avaliação, Campinas, v. 3, n. 4, p. 29-35, dez. 1998b

DIAS SOBRINHO, José. Editorial. Avaliação, Campinas, v. 4, n. 1, mar. 1999a.

DIAS SOBRINHO, José. Editorial. Avaliação, Campinas, v. 4, n. 2, jun. 1999b.

DIAS SOBRINHO, José. Editorial. Avaliação, Campinas, v. 5, n. 3, set. 2000 .

DIAS SOBRINHO, José. Avaliação: técnica e ética. Avaliação. Campinas, v. 6, n. 3, p. 7-19, set. 2001 .

DIAS SOBRINHO, José. Editorial. Avaliação, Campinas, v. 6, n. 3, set. $2001 b$. 
DIAS SOBRINHO, José. Entrevista concedida a Gladys B. Barreyro. 2009.

FOUCAULT, Michel. Microfísica do poder. Organização e tradução de Roberto Machado. 6. ed. Rio de Janeiro: Graal, 1986. 318 p.

GONÇALVES FILHO, Francisco. Enfoques de avaliação institucional em revista: um estudo da revista Avaliação (1996-2002). 2003. 183f. Dissertação (Mestrado) Faculdade de Educação. Universidade Estadual de Campinas, Campinas, 2003.

LEITE, Denise. Avaliação e tensões Estado, Universidade e Sociedade na América Latina. Avaliação, Campinas, v. 2, n. 1, p. 7-17, mar. 1997

\section{LEITE, Denise. Entrevista concedida a Gladys B. Barreyro. 2009}

PALHARINI, Francisco de Assis. Revista Avaliação: pólo de resistência da avaliação institucional. Avaliação, Campinas, v. 8, n. 1, p 37-58, mar. 2003

PALHARINI, Francisco de Assis Tormento e Paixão pelos Caminhos do PAIUB. Avaliação, Campinas, v. 6, n. 1, p. 15-26, mar. 2001.

RISTOFF, Dilvo. Entrevista concedida a Gladys B. Barreyro. 2009

RISTOFF, Dilvo. Avaliação Institucional e a Mídia. Avaliação, Campinas, v. 2, n. 1. p. 61-64, mar. 1997.

RISTOFF, Dilvo. Introdução: princípios do programa de avaliação institucional. Avaliação, Campinas, v. 1, n. 1, p. 47-53, jul. 1996.

RISTOFF, Dilvo. A tríplice crise da Universidade Brasileira. Avaliação. Campinas, v. 4, n. 4, Separata, p. 9-14, set. 1999.

RISTOFF, Dilvo. O Exame Nacional de Curso e a Avaliação Institucional, Avaliação, Campinas, v. 6, n. 3, p. 21-29, set. 2001.

SANTANA, Ariana Souza de. A produção documental da Rede de Avaliação Institucional da Educação Superior (RAIES) e as políticas de avaliação da educação superior brasileira. Relatório final. Programa Ensinar com Pesquisa. Universidade de São Paulo, EACH, ago. 2009.

SORDI, Mara Regina Lemes de. A Face perversa da avaliação: elementos para uma leitura do papel da avaliação no projeto neoliberal. Avaliação, Campinas, v. 3, n. 1, p. 51-57, mar. 1998. 
TRINDADE, Hélgio. A avaliação institucional das universidades brasileiras: resistência e construção. Avaliação, Campinas, v. 1, n. 1, p. 9-14, jul. 1996. TRINDADE, Hélgio. Entrevista concedida a Gladys B. Barreyro. 2009. ZAINKO, Maria Amélia Sabbag. Entrevista concedida a Gladys B. Barreyro. 2009. 